\title{
Ancient and Modern Conceptions of Charity: Orthodox Judaism and Effective Altruism
}

\begin{abstract}
Judaism has a strong commitment to charity, and both serves as an inspiration for many effective altruists, and is an inspiration for the concept of tithing, which has been adopted by and adapted to effective altruism. At the same time, the Orthodox Jewish structure of Halacha has complex boundaries and requirements which at least appear to be at odds with key tenets of effective altruism, including consequentialism and effectiveness. This chapter explores those tensions, especially between the individual obligations posited by Judaism and those imposed by strict utilitarianism. While Halacha is unyielding to fundamental change, it is also relevant to and often compatible with concerns which inform effective altruism, including consequentialism and prioritization. Other key points of disagreement, such as placing priority on supporting basic needs of family before those of strangers, are irreconcilable in theory but seem to dovetail with the practice of effective altruism. The chapter concludes with thoughts on how ideas about evaluation and effectiveness are both compatible with and should inform the practice of Orthodox Jewish charity organizations in the future.
\end{abstract}

\section{Introduction}

Orthodox Judaism has a long and complex history of engaging with contemporary moral and ethical concerns. Engaging with the modern theses of effective altruism (EA) makes a number of these historical debates and concerns relevant, and raises new concerns and questions that can be analysed through similar lenses. Peter Singer, one of the original promulgators of EA, defines it in his book on the topic as "a philosophy and social movement which applies evidence and reason to working out the most effective ways to improve the world." 1 Singer, an applied ethicist in the utilitarian tradition, notes that this "is a vague idea that raises many questions," and without imposing or implying a non-existent consensus within the movement, provides guidance on what the generally accepted principles of EA are, and where there is diversity of opinion.

It cannot be argued that Orthodox Judaism, with its unyielding emphasis on Halacha as the arbiter of correct action, ${ }^{2}$ is compatible with the framework or assumptions of EA, but neither can it be reasonably claimed that EA is irrelevant to Jewish moral concerns. For this reason, it is worthwhile

1 Singer, The Most Good, 4-5.

2 Bleich, Perfect Faith; Broyde and Pill, Setting the Table; Walter, Halachic Decision; Soloveitchik, Halakhic Man. 
to review a number of the central tenets of EA and situate them within the context of both ancient and contemporary Jewish debates, without attempting to resolve the various tensions. This paper focuses on four central issues that define EA and distinguish it from other contemporary moral philosophies: (1) the moral obligation to help others, (2) consequentialist and utilitarian reasoning about altruistic behaviour, (3) prioritisation of causes, and (4) the use of reason and evidence to understand effectiveness. After discussing the first three, and reviewing some difficulties understanding Judaism's approach to the fourth, the paper concludes with observations about how reason and evidence are required in normative Jewish law (Halacha), and how the standard will need to continue to evolve as it relates to charitable giving.

\section{The Jewish Obligation to Give to Charity}

It hardly needs to be said that charity is a critical value in Judaism, although perhaps it is worth noting that the EA movement draws inspiration for the requirement to give specifically $10 \%$ to effective causes from the Jewish (and later, Christian) practice of tithing. The question of consequentialism with regard to charitable giving, and the universalist foundations of EA, are more complex. In order to discuss the question of moral obligation clearly, we need to first introduce Jewish Law. While a complete overview of Jewish law is beyond the scope of the current paper, a few key notes on the topic are necessary for understanding the sources cited and their relationships. Following this background, we introduce first biblical, then rabbinic, obligations to give to charity. Finally, we compare the religious obligations in Judaism to moral obligations as they are understood by EA.

\subsection{Introduction to Jewish Sources and Law}

There are two classes of Jewish law: biblical and rabbinic. Biblical law, as the name implies, is based on the Jewish Bible, and on the interpretation and exegetical rules passed down from Moses. The tradition notes that the Bible empowers rabbis to both define how certain biblical rules apply and to safeguard and apply the law. ${ }^{3}$ The biblical commands are limited to those written in the Pentateuch and the unwritten laws traditionally understood

3 For instance, while the mandate to pray to G-d is certainly biblical, the rabbis formulated a specific structure of prayer, and the requirement must therefore be fulfilled using the structure of prayer devised by the rabbis. 
to have been given directly to Moses at Sinai. The Jewish Bible is used in rabbinic literature as a source of rules only as they are interpreted in light of the tradition.

Critical to understanding Jewish law is the power given to the rabbis at Mount Sinai to codify the rules and (within specific parameters) create new rabbinic laws. The transmission of the combined biblical and rabbinic law means that Halacha is not based directly on the text of the Bible. Instead, it is based on the tradition: first the codified oral tradition and law called the Mishna, finalised ca. 200 C.E., and mishnaic literature, then talmudic literature, finalised ca. 600 C.E.

Mishna and mishnaic literature are the oral traditions of the Law passed down through the generations to the rabbis in the generation after the destruction of the second temple. The Mishna was codified ca. 200 C.E., and both Mishna and other mishnaic literature contain statements and laws attributed to scholars living before that time. Talmudic literature primarily means the Babylonian Talmud, recording discussions that occurred between 200 C.E. and 600 C.E. These discussions include analysis of the Mishna, explanations of how verses of the Bible lead to the law, and interpretation and elucidation of other sources. ${ }^{4}$ The analysis in large part explores and explains the relationship between biblical law and the text of the Bible, and the origins and structure of rabbinic law. For this reason, this literature is understood to reflect the entire historical transmission of the law, ${ }^{5}$ and is the basis for all later discussion of Jewish law.

Following the codification of the Talmud, there were further eras of the development of Halacha, each of which is defined by a conclusive codification. ${ }^{6}$ Talmudic literature debated and discussed by medieval commentators, rabbinic authorities living in the few hundred years prior to ca. 1500 C.E, is known as Rishonim (literally "early ones"). This period ended with the definitive work on Halacha, the Shulchan Aruch, by Rav Yosef

4 This literature extends beyond the Babylonian Talmud, however, and the discussions span secondary texts such as early extra-mishnaic texts such as Baraita and the Tosefta, and are recorded in texts outside of the Babylonian Talmud - including the Jerusalem Talmud, Midrash, (primarily homiletical exegesis with some Halachic content), and other similar sources from that period.

5 Jewish tradition maintains that these texts primarily codified (formerly orally transmitted) rules and knowledge that would otherwise have been lost during the few centuries following the destruction of the second temple and exile.

6 There are specific implications to the codification of the rules at each point. For instance, an explicit rule decided in the Talmud continues to apply, often even when the reason given is no longer applicable. 
Caro, published in 1565, along with the now universal inclusion of the gloss by Rabbi Moshe Isserlis, first published in 1578. This text, like the Talmud before it, was universally accepted by Jewish religious authorities.

Later work in Halacha consists partially of Shailos u'Teshuvos, compendia of questions and answers about Jewish law, as well as commentaries and super-commentaries to the Shulchan Aruch, written by the Acharonim (literally "later ones"). As our discussion will find, these can revisit questions of biblical and rabbinic sources, within the structure of the tradition, as well as discussing novel situations or questions.

It is critical to note that the decisions of later eras of Halacha traditionally do not contradict the decisions of earlier eras, so that the Shulchan Aruch does not contradict the Talmud, nor Acharonim the Shulchan Aruch. Given this, however, the later opinions do decide between different opinions or interpretations of the texts written in each earlier era. ${ }^{7}$ For that reason, normative Halacha does not typically follow the earliest decision, but the latest one, and each generation is told to follow the Halacha as decided in their generation. For this reason, the most recent works illuminate how the decisions cited in the earlier sources are in fact relevant to Jews today. ${ }^{8}$ The focus on modern sources is important because we are interested in current and near future interpretations, rather than a purely historical analysis. At the same time, given the structure of Halacha, it is useful to examine sources relevant to each question via exploring the earlier sources.

\subsection{Biblical Origins}

"If there is among you a needy person, from among your brothers, in your cities, in the land the Lord, your G-d, is giving you, you shall not harden your heart, and you shall not close your hand from your needy brother. Rather, you shall open your hand to him, and you shall lend him sufficient for his needs, whatever he is lacking. ... For there will never cease to be needy within the land. Therefore, I

7 This treatment is necessarily simplistic, as "the methodology by which some opinions are accepted and others excluded from application to practice constitutes a highly complex aspect of Halakhah." (Bleich, Contemporary Halakhic Problems, xvi).

8 Note that the current discussion is restricted to those who have maintained fidelity to this Halachic structure. This paper therefore excludes the approaches of the (comparatively very recent) Reform, Conservative, and other "Modern" movements which modify (rather than interpret and apply) the traditional law, or that abandon Halacha entirely. 
command you, saying, you shall surely open your hand to your brother, to your poor, and to the needy in your land." (Deut. 15:7-11)

While a variety of biblical texts discuss charitable giving of various sorts, the one most relevant to modern charitable giving is the above passage in Deuteronomy. ${ }^{9}$ Per later sources, the exact phrasing of these verses is critical in understanding the contours of the obligation. For example, a discussion that becomes critical to the question of moral obligation is that verse 7 uses the terms "among you," "needy person," "in your cities," and "in your land." According to the Sifrei, ${ }^{10}$ the order indicates a preference for the recipients of giving, so that according to most opinions, physical location creates a biblically mandated preference, albeit one that may be overridden by different levels of need.

Still, the biblical obligation laid out in Deuteronomy provides a baseline rather than a complete picture. The Shulcan Aruch notes in the very first rule about charity that the Bible repeatedly exhorts Jews to assist others by giving to charity, emphasising its importance. (Shulchan Aruch, Yoreh Deah 247). In addition to the theoretical discussion of importance, the actual emphasis on charity by Jewish communities is clear historically. Gregg Gardner presents a lengthy account of rabbinic obligations of charity, ${ }^{11}$ which focuses on the early development of communal support for the poor in the 2 nd to 5 th centuries C.E. The evolution of views during this time makes it clear that in place of the agricultural charity that prevailed in the agricultural society of Judaism in Israel, ${ }^{12}$ the rabbis viewed redistribution of wealth to the poor to be a central function of post-temple Judaism.

9 While the deontological/utilitarian distinction is not always a useful way of thinking about Halacha, other biblical forms of charity seem to be more deontological than Tzedakah. Specifically, the laws relevant to agriculture inside of Israel are detailed requirements rather than being primarily goal-oriented. In those laws, the Bible commands Jews to give a portion of their produce to the poor in several ways, by leaving a portion at the corner of each field of grain unharvested (Lev. 19:9-10), to leave additional parts unharvested (Deut. 24:19-21), to separate an additional portion for the poor during certain years of the sabbatical cycle (Deut. 14:28 and 26:12) and to leave the entire crop to be harvested by the rich and poor alike in the sabbatical year. In addition, there are non-agricultural requirements that apply outside of the narrow remit of farming which are also not strictly considered Tzedakah, such as the requirement to extend interest-free loans to brethren, so as not to oppress them.

10 A pre-talmudic compilation of biblical exegesis.

11 Gardner, Origins.

12 This is also an example of how Halacha remains binding, since these laws are once again practiced. 


\subsection{Rabbinic Obligation}

The rabbinic obligation to give charity is based on the biblical idea of giving a tenth of a person's wealth to the needy. This was introduced by Abraham when he said, in Genesis 14:20, that he would give a tenth of his wealth to a priest of the Lord. Fourteen chapters later, Jacob accepts this obligation on an ongoing basis, saying that he will give a tenth of whatever he receives. This is not itself an obligation for future generations to give a tenth of their non-agricultural income, but forms the conceptual basis for the requirement. ${ }^{13}$

The way in which one fulfils this obligation is the subject of much discussion. There is some talmudic debate, but most of the discussion about the allocation of charity appears in later sources. For instance, there is a distinction drawn between charitable giving to community institutions and charitable giving to the poor. For example, Nachmanides' explanation, found in his commentary on Deuteronomy 12:6, discusses Exodus 35:24, where a surplus of funds is available for building the tabernacle, and the point is made that communal needs are limited, unlike personal donations. Once those needs are fulfilled, as seen in Exodus, communal leaders are responsible to stop further giving. No such limitation exists for giving to the poor, and while each individual has a limited requirement, the obligation to give remains.

There is also a critical point to make about the structure of giving in Jewish law. For historical and religious reasons, charitable giving from Mishnaic times (ca. $200 \mathrm{CE}$ ) to the late Middle Ages was in large part routed through Kupot, communal charity funds. Many such funds exist today, albeit sometimes in the guise of a "Rabbi's discretionary fund" or similar. These funds are not extraneous to the rules, and have their own set of guidelines in Halacha. For example, an individual may be required to give to these funds, or at least primarily to these funds, and may fulfil their individual obligation to give via donating to these funds. ${ }^{14}$ The personal

13 There is some discussion about the origin of the obligation to give a tenth of income. Some, such as Tosfos Taanit 9a, "You shall surely Tithe", Ohr Zarua 1:13 8b, and Sefer Chasidim 144:1, seem to say it is an obligation derived via exegesis, while other sources refer to it as a rabbinic enactment, or as a binding (and required) tradition.

14 For support for this claim, see the discussion in Shulchan Aruch, Yoreh Deah 250:4, and the commentaries discussing the way in which a poor person who voluntarily withdraws from the Kupah system and collects from door to door potentially loses rights to charity. 
obligation to give still has its own set of priorities, but the structure of these funds is critical for questions considered later.

\subsection{Comparing the Obligation to Give ${ }^{15}$}

Peter Singer makes the clear case in his book Practical Ethics that the wealthy have a moral obligation to help the poor on utilitarian grounds. The rich have sufficient resources, and even for someone with only somewhat utilitarian beliefs, a person should certainly be willing to sacrifice at least a small portion of their own comfort to help others, providing great benefit at very low cost.

Judaism takes a comparable view of the obligation regarding Tzedakah (Charity, or translated literally, Justice), albeit from a markedly non-utilitarian viewpoint; "He who ignores those in need is called wicked and is regarded as if he worships idols" (Shulchan Aruch, Yoreh Deah 247:1). The deontological prohibition against turning away the needy, "shutting your hand" (Deut. 15:7) from helping them, has a clear biblical source. Expanding on this, the latter clause of the Shulchan Aruch suggests an equivalence with idol worship, a sin considered on par with murder, deriving from the fact that all wealth comes from G-d, as the Rema's gloss notes just afterwards; "People must realise that they themselves are given sustenance by G-d," (Rema, Yoreh Deah 247:3) and failing to use the wealth granted by G-d to help others would, by this logic, be considered rejecting G-d. This argument's source can be traced to a passage in the Talmud (Kiddushin 82b): "Poverty does not come from a trade, nor does wealth come from a trade; rather, they come from the One to Whom wealth belongs, as it is stated [citing the verse in Haggai 2:8]: 'Silver belongs to me, Gold belongs to me, says the Lord of hosts." 16

Returning to the comparison to EA, some object to Singer's view on the non-utilitarian grounds that the moral choice to help the poor is only important if donations are, in fact, made by choice. ${ }^{17}$ Given that objection, it is worth noting that Judaism rejects this logic; in many cases, those who

15 Note that Judaism has a somewhat more segmented view of altruism than the EA community does, and views financial support, Tzedakah, as a separate obligation from other Chessed. The broader view of different but related obligations in Judaism is an important issue for the compatibility with EA views, or lack thereof, but will not be discussed in detail here.

16 See Derech Eretz Zuta 4:1 and Midrash Tanchuma, Mishpatim 12:4 for parallel exegesis.

$17 \mathrm{Yu}$, "Obligation to Donate." 
do not donate by choice can be compelled by the court to do so. ${ }^{18}$ At the same time, Jewish law does allow a great deal of latitude and choice in the selection of recipients and causes.

\section{Consequentialism within Deontological or Moral Reasoning}

In this section, we will review the halachic basis and practice of charitable giving in Judaism, and suggest where consequentialism is still relevant. First, we will show that consequences matter within non-consequentialist explanations, even according to those embracing the deontological approaches of Halacha. Following this, we will discuss the rules of prioritisation for giving in Halacha, and why claims that these rules are incompatible with utilitarian concerns are misplaced. After noting a tension between individual and communal responsibilities, which we will return to in a later section, we finally note that the virtue-ethical approach which some (non-halachic) Jewish sources present also seems to indicate that there is a need to include some focus on consequences.

\subsection{The Deontological Basis of the Requirement}

Jewish Law has a clear deontological basis in doing the will of G-d. Medieval authorities suggest that even when Commandments (Mitzvot) have clear reasons, it is less important to find or understand those reasons than it is to simply perform the commanded act - and that our understanding of the reasons in no way modifies the command. ${ }^{19}$ In other interpretations, the laws are pathways to moral perfection, and the performance of commandments is based on a more selfish (if arguably more consequentialist) reasoning.

At the same time, there are external consequentialist factors that determine what can, and must, be done to fulfil deontological or moral obligations, and this seems particularly applicable to the laws concerning charitable giving, where the obligation is fulfilled by giving which has a positive impact. ${ }^{20}$ Specifically, if money is given in charity but, for instance,

18 Shulchan Aruch Yoreh Deah 248:1.

19 This seems to match some versions of divine command theory, but the conflation of Jewish and Christian views involved in many discussions of divine command theory, and the lack of clarity about what divine command theory in Judaism would mean, makes this unreasonable for reasons beyond the scope of this paper.

20 For example, see various commentaries on Talmud Bavli, Bava Basra, 10b-11a. 
stolen before the recipient receives the money, the obligation is unfulfilled. Conversely, as noted above, if a person is forced by the courts to give, they fulfil the commandment.

\subsection{The Virtue Ethics View}

The above technical point about when the obligation is (not) fulfilled does not obviate the moral interpretation of charity, famously embraced by Rabbeinu Yona in his The Gates of Repentance, ${ }^{21}$ and in the Sefer HaChinuch when discussing forgiving loans to the poor. ${ }^{22}$ As we will note, loans are a primary source for these laws. The moral interpretation sees the idea of lending as a way for people to become more empathetic and become more similar to G-d, who is the ultimate source of support for everyone. This interpretation is widely accepted, but is not exclusive. That is, the moral aspects of the law do not replace the technical obligation noted above. Furthermore, it seems there is an intuitive justification, which is that building moral character is not accomplished by ignoring consequences.

As an additional point, as Rabbi Shimshon Rafael Hirsh notes in volume 3 of his collected writings, in practice each Jew is themself interested in doing good in the best way possible. That is, he notes that there is an intrinsic desire to do good, and therefore suggests that accomplishing good in the world is how individuals achieve morality. As suggested above, those who promote ethical perfection as morality in Judaism still seem to insist on a somewhat consequentialist viewpoint when discussing how ethical perfection is achieved. In other words, focusing on ethics independent of actual consequences seems to be rejected.

\subsection{Priorities in Charity}

The most important discussion in Jewish sources relevant to the question of consequentialism and moral priority for charity is the debate about the proper order of preference and allocation of charitable giving. The first source in this discussion is the talmudic discussion in Shabbat (63a), "Rabbi Abba quotes Rabbi Shimon ben Lakish as saying that loaning is a greater form of charity than gifts, and entering into business with the poor person is even better." Some commentaries claim this precedence is because in these cases the needy person is not embarrassed when receiving the assistance,

22 Sefer HaChinuch, Commandment 477. 
while others, such as the Chidushei Agadot, say that it is because the person is able to support themselves (rather than requiring further assistance).$^{23} \mathrm{In}$ either case, the result is not justified by any deontological argument. The priority is based on the outcome - at least because it allows dignity on the part of the recipient, and also because it creates a longer lasting benefit of self-sufficiency.

There is a common thread in the discussions of charitable giving; prioritising is based on external consequentialist factors and maximising positive impact is seen as critical. The primary source for this is Maimonides, who delineates eight levels of charitable giving, ${ }^{24}$ where the highest levels are the most helpful and least insulting to the poor, thereby prioritising not just their physical needs, but their emotional and other preferences or needs. Seemingly based on the talmudic passage cited earlier, charity which enables the poor to provide for themselves is cited as the most preferred method. ${ }^{25}$ This preference among types of giving is included in the Shulchan Aruch nearly word-for-word, and this basic ordering of preference is essentially unchallenged in later sources.

We note that this idea of precedence among ways of giving is sometimes misunderstood, and in at least one case, an attempt is made to claim that these rules show Jewish law for charity is anti-utilitarian. Michael Harris states that this anti-utilitarianism is implicit in Maimonides' ruling (which in fact comes from the Talmud, Kesuvos 67b) that we must even give to a previously wealthy pauper according to his former status, purportedly proving that this is a deontological requirement rather than, and incompatible with, a utilitarian one. ${ }^{26}$ While there is a deontological component, as noted above, a review of this particular claim shows how in such cases the preferences are clearly utilitarian.

Harris says that "whilst a utilitarian would undoubtedly grant moral weight to the previously wealthy person's pain at not having his subjective needs fulfilled, greater utility would surely be achieved by using available charitable funds to satisfy the basic needs of many rather than to guarantee the comfort of the few." However, Harris is mistaken in the inference that

23 While the original sources do not put this in terms of economic efficiency, it seems arguable that this is at least part of the reasoning, per Maimonides' preference for prioritising the most helpful types of charity, such as setting up someone in a business rather than directly giving money.

24 Maimonides, Mishneh Torah, Gifts to the Poor, 10:7-18.

25 In fact, according to many authorities, those that fail to provide for themselves despite the ability to do so have no right to accept charity. Tur Yoreh Deah 255:1.

26 Harris, "Consequentialism." 
this ruling prioritises the single rich man over multiple poor people. To start, Maimonides' phrasing implicitly clarifies this is an extreme rather than a typical case, saying that we give "even" that much - implying that it is a less pressing priority. An even clearer refutation is included in both the definitive compilation of the Tur, and then the Shulchan Aruch (Yoreh Deah 251:7), where they note that more basic needs have precedence. It is also rejected explicitly by modern authorities, such as Rabbi Ari Marburger. Marburger addresses the logic of Harris's claim, clarifying that "although a particular pauper may claim a high standard of living, if there are limited funds, we focus on the other paupers that have more basic needs." 27 This does not prove a consequentialist viewpoint, much less a utilitarian one, but neither does it conflict with such an understanding.

To briefly return to the discussion of the technical obligation, we should note that while the requirement to give is on the individual, decisions about allocation and level of need, as well as the requirement to give according to the standard the recipient is accustomed to, are typically made by a communal fund (Rema's Gloss to Shulchan Aruch, Yoreh Deah 250:1). This seems to imply that the allocation decisions need not be a moral decision strictly on the part of an individual, since they can be delegated. This delegation also becomes critical in our later discussion, where we argue it indicates compatibility with EA, albeit for other reasons.

\section{Comparing Effective Altruism to the Prioritisation of Giving in Jewish Law}

Certain factors are regarded as morally clear by most in the EA community. Among these, EA assumes three things which are discussed in Jewish Law; (1) The moral need to help those in need, (2) the lack of moral relevance of physical distance, and (3) the relative priority of more needy individuals, at least when the ability to help is equivalent. The first was discussed above, and while Jewish reasoning about the second two factors clearly differs, there are parallels in Halacha to each of these claims, and the parallel is even closer when considering the practice of EA.

The rules of precedence of recipients in individual giving are (despite minor differences) widely accepted among medieval commentators and Halachic authorities. For example, the first requirement is ensuring one's family has sufficient funds. These rules seem to imply that a person is not 
obliged to give money to others before first fulfilling his own needs, then his immediate family's needs, and finally his extended family's needs. In all cases, as further discussed below, this is limited to basic personal and family needs.

Once those basic needs are met, charitable funds are available to be spent on others with greater needs. Similarly, we find that fulfilling the basic needs of others comes before being available for further charitable spending. This prioritisation does not, however, require effectiveness from the giver. Specifically, the order of precedence seems to be non-mandatory for the individual, ${ }^{28}$ and they are allowed to give at least a portion of funds to lower-priority, less pressing causes or individuals. ${ }^{29}$ At the same time, as we will argue below, it seems that this prioritisation based on impact and importance is, or at least might be, binding on Kupot.

We note that EA as a movement takes a similar tack when suggesting that the world's richest people, whose personal needs are already fulfilled, should donate effectively. These are people whose needs, and their immediate family and friends' needs, are already met. In this way, we see that EA has a similarly tiered view of needs in practice, as even its most strident advocates ensure that they have sufficient personal income, and can provide for their immediate families at a level far exceeding that of the poorest individuals in the world. From a strictly utilitarian viewpoint, this would be at least arguably immoral, but Halacha embraces a more pragmatic viewpoint, closer to that of actual practice in EA.

28 As cited in Footnote 13, per the Sifrei, the precedence is biblical, but that exegesis also explains the phrase "which he is lacking" as granting greater precedence to those with greater need, overriding the other preferences. Chasam Sofer, a modern commentator, notes that the order is a preference, not a strict exclusion of later levels, and that greater needs would obviously take precedence, in the second volume of his commentary to Shulchan Aruch Yoreh Deah, Section 234.

29 Cf. Tana D'Bei Eliyahu 27, which explicitly says that one must feed the highest priority relatives, and only the remaining money should be spent on the next priority level. This, however, refers only to providing sufficient food, and perhaps implies that food for strangers would precede housing and clothing for relatives, even when lives are not in danger. Note that while this compilation was finalised in the 10th century C.E., it significantly predates, and is cited by, the Talmud. 


\subsection{The Moral (Un)importance of Distance}

There is an argument in Peter Singer's article "Famine, Affluence, and Morality," which dismisses the moral relevance of distance. This has been embraced by effective altruists, and forms one of the two key justifications, along with relative need, for advocating for charity for the world's poorest people. While this approach is certainly not reflected in Halacha, the difference in approach could easily be misunderstood to strongly conflict with Singer's claims. Given this, it is worth considering the question of geographic preferences in Halacha in a bit more detail.

The first issue in Jewish religious sources that relates to geographic location derives from a simple question. Does the negative commandment to not ignore the needs of others apply only when one sees a poor person, or does the mere knowledge of the needy person trigger this obligation? Maimonides and the Sefer HaChinuch, at least, seem to agree with Singer's (much later) argument that there is an obligation to give once a person knows a need exists, regardless of distance.

The Sefer HaChinuch, in his explanation of commandment 478, interprets the biblical command to not "'withhold kindness and charity from our brother Israelites...' since we know the weakness of their situation, and we have the ability to assist them." This is clarified by the contemporary authority Shmuel HaLevi Wosner (1913-2015). He states that

\footnotetext{
"it seems clear to me that we are not discussing a case where the pauper is in front of you begging... and it seems this issue is the dispute between Maimonides... where he says that it is enough to know the poor person exists... [and the Rashba] ${ }^{30}$ does not have this implication, since he says the poor person must be in front of you, requesting money" (Shevet HaLevi, 9:199).
}

In his conclusion, Wosner says that not only must one give whenever a need is known, but that this obligation to not ignore the needs of others, is paramount if the need is for survival or basic needs. On this basis, he maintains that donations to the poorest and most needy recipients take precedence over other less impactful and less pressing charitable needs.

Despite this conclusion - namely, that one may not refrain from giving on the basis of distance - there is a clear geographic precedence included in the prioritisation of needs. As we will see, the moral approach of Halacha differs from that of EA due in large part to the latitude provided to givers to choose causes and specific recipients.

30 A second medieval commentator who disputes Maimonides' view on this point. 
Following one's family, the rules of priority discussed earlier specifically give precedence to those in the giver's neighbourhood, then their city, and next to paupers in Jerusalem, and finally to those located elsewhere. The requirement to give to people anywhere discussed above, however, is a biblical one. This is per the Talmud, (Bava Metzia 31b), which interprets the repetition of the word "open" in Deut. 15:11, “...therefore I command, open, open your hand to the poor and needy in your land" to require giving not only to those in one's own city, but those who live anywhere in the world. Interestingly, this ruling is interpreted in the Shulchan Aruch to imply that those in one's own city have precedence, and those located elsewhere are secondary. ${ }^{31}$ At the same time, as we will note below, this geographic precedence is limited.

\subsection{Applications and Implications of Precedence}

A question remains concerning how the requirements of precedence operate in practice. From at least one viewpoint, precedence comes from the requirement that Kupot support those to whom the money was donated. From this perspective, we note that in general one who donates to a local charity intends to support their local community first, and so the charitable fund must respect that. This is the subject of talmudic debate (Bava Batra $8 \mathrm{~b}-9 \mathrm{a})$, and the advice is given that the charity collector can explicitly condition giving to the fund on the discretion of the people appointed to run the fund, as explained in the talmudic passage, quoted below.

"Rabba [a talmudic sage] would make two purses [when collecting], one for the poor of the rest of the world, and one for the poor of his city. Once he heard what Shmuel said to Rav Tahalifa bar Avdimi: 'Make only one purse, and make a stipulation about [what the money will be used for],' so Rabba made that stipulation. (The commentary of Rashi explains, "stipulate to the people of your city that the money will be given to whomever needs.") Rav Ashi [another sage] said 'I do not even need to make a stipulation, because whoever donates relies on my discretion."

Despite the stipulation giving an ability to a communal fund to distribute funds elsewhere, there remains the geographic preference which is biblical in origin, as noted above. ${ }^{32}$ Two points can be made to explain this. Firstly, the apologetic answer is that in the ancient or medieval world, the ability to give to those geographically distant from one's self was very limited. Perhaps

31 The source for the preferences is complex, based on the verse in Deuteronomy cited above.

32 See the Sifri's biblical exegesis cited in footnote 13. 
this logic is the source for the Talmud's assumption that local paupers are included, but an extra word is used to include those elsewhere. Secondly, according to accepted Jewish law, geographic distance is only relevant when people in each place have similar levels of need. ${ }^{33}$ This is implicit in the Shulchan Aruch (Yorah De'ah 251:7) where it states that paupers needing food always precede those who need clothing or other goods. ${ }^{34}$ This precedence is expanded upon in modern rulings to refer to any difference in levels of need. If interpreted very broadly, this might imply that geographic precedence is merely a tiebreaker for otherwise identical needs, although no halachic authority seems to go quite that far.

As a concluding point, it is interesting to note that, just as EA suggests neglectedness as a criterion, something akin to the economic concept of replacement value is considered in Halacha. Specifically, those who can receive charity from elsewhere are considered lower priority than those who cannot, though no explicit formulation of how this affects precedence is given (Yisrael Meir Kagan, Ahavas Chesed 6:3, published 1888). This seems to show that a conceptual understanding of marginal effectiveness with regard to giving, at least, is compatible with Halacha.

The above provides some understanding of needs, neglectedness, and the halachic basis for prioritising need over location. Based on this, we will suggest below that it seems plausible that modern Jewish law regarding charity funds, though not individuals, effectively matches the EA position that those who would be helped most should be given precedence when facing limited charitable resources.

\section{Effectiveness, Reason, and Evidence for Charitable Giving}

Related to the discussion about precedence between various needs is the question of effectiveness. In EA, a central debate concerns cause prioritisation and effectiveness. For example, there has been discussion about whether it is better to give money directly - to save human lives by funding anti-malarial nets, for instance - or to promote economic growth and save lives more indirectly. Similar issues have been raised by effective altruists about the relative importance of alleviating suffering versus saving lives,

33 See commentary to Yoreh Deah 251:7. For the modern ruling, see Yosef Fleischman, Beis Din Nesivos Chaim, who discusses this in a blog post: http://dinonline.org/2010/08/ 12/laws-of-tzedakah-part-ii-who-to-give-first/.

34 This is, according to Vilna Gaon's explanation there, based on a passage in the Jerusalem Talmud in Horayos, Chapter 3, Section 4. 
though on this point Judaism is unambiguous about the preference for the latter. 35

The consensus in EA is that while the relative values and importance of different causes is a critical concern, individual givers can and should have their own values, and make their own choices about giving.

While critical to our discussion, it is unsurprising that the idea of effectiveness in charitable giving as understood today is nowhere to be found in early Jewish sources. Not only is the idea of efficiency a modern, industrial one, ${ }^{36}$ but the tools needed to evaluate effectiveness, such as cost-benefit analysis, are very recent, and only truly started to be used in the second half of the 20th century. ${ }^{37}$ Despite this, there are both relevant discussions in modern Halacha, and at least two reasons to suggest that the question of effectiveness could and should become more widely discussed in Halacha.

Rav Yosef Fleischman cites Chasam Sofer (YD 231) as implying that we have an obligation to "investigate and compare the poverty levels of the poor" in order to prioritise charitable giving. In contrast, the preeminent Halachic decisor of the previous generation, Rabbi Moshe Feinstein, (1895-1986), rules in his compendium of Halachic responsa, (Iggros Moshe Yorah De'ah 1:144,) that an individual is allowed a wide amount of latitude in choosing the recipient of their charity. The individual is legally entitled to this discretion. He clarifies that this follows a logic from a variety of talmudic sources where the money is ought to someone, but the benefit of choosing the recipient (Tovas $\mathrm{HaNa} \mathrm{a}^{\prime} \mathrm{h}$ ) is reserved for the giver. For this reason, not only is an individual not required to investigate where the need is greatest, but they can even ignore that information once it is available.

But even according to Rabbi Moshe Feinstein, the same leeway is explicitly not given to Kupot, the charitable funds. This is for two reasons, the first of which, the requirement to give according to relative need within the local geographic areas, is discussed above. The second reason, the responsibility of the fund to fulfil the will of the givers, is a very general requirement that we will argue has several important consequences.

First, the money given to the fund seems to be able to be distributed at the discretion of the individuals in charge of the fund, as noted in the talmudic debate quoted above, (Bava Batra 8b-9a). In general, however, there is a central fund, and in such a case the discretion is transferred from

35 The Halachic position on population ethics is an interesting but seemingly unaddressed topic.

36 Alexander, "Efficiency."

37 Pearce, Cost-Benefit Analysis. 
the individual to the community, where the use of evidence seems to be required. This is explained in Shulchan Arukh, Yoreh De'ah 251:5, "Once a man has contributed a sum of money to the Gabbaïm, neither he nor his heirs have any power over it, but the community can do with it what is pleasing in the eyes of G-d and man.” There is a presumption that the funds were intended for the local poor, and per 256:3, the primary responsibility of distributing funds is given to a panel of three people, who are required to judge the needs of individuals and distribute according to them. This, it seems, explicitly requires their reliance on evidence, albeit far more weakly so than EA. At the very least, Halacha strongly endorses a responsibility to some level of stewardship, as noted below, in Shulchan Aruch Yorah De'ah 257. Being a responsible steward, it is therefore clear that the charity should allocate funds to maximise effectiveness within the community, rather than allocate, for example, on a first-come first-serve basis.

The limitation to within the community, however, only applies to charity given to a fund where the explicit purpose is the local poor, ${ }^{38}$ and, even in that case, not only can that fund exercise discretion about which individuals are most needy, but it could also decide, as the talmudic discussion implies, to allocate the money to those in need elsewhere.

The obligation is further explained in Shulchan Arukh, Yoreh De'ah 256-257, which contains a variety of requirements about avoiding even the appearance of impropriety. In the modern context, it seems that these rules imply that charitable funds must abide by at least the norms of proper management, which include a variety of ethical standards and both accountancy and accountability practices.

For basic requirements of non-profit organisations, there is a precept in Halacha that in a wide class of cases secular law is as binding on Jews as a religious requirement. Beyond that, however, it seems clear from Yoreh De'ah 257:1-2 that charities are required to go beyond standard practice in avoiding any appearance of impropriety. If givers expect non-profits to demonstrate outcomes and effectiveness, it seems that these standards would become required according to Halacha as well. ${ }^{39}$

38 And this was a strong historical norm, to which the Shulchan Aruch notes he has never heard an exception.

39 For basic requirements of nonprofit organisations, there is a precept in Halacha that in a wide class of cases secular law is binding on Jews as a religious requirement. Beyond that, however, it seems clear from Yoreh De'ah 257:1-2 that we require charities to go above standard practice in avoiding any appearance of impropriety. 


\section{Conclusion}

It should be clear that Halacha is its own system, and any attempt to fit it into another framework is fundamentally misguided. At the same time, Halacha is aware of and engaged with the reality of charitable giving, and this means that the concerns of EA are relevant, not to guide or change Halacha, but to inform it. This includes the ability to influence individual charitable decision making, which allows a degree of latitude in cause prioritisation, allowing people to embrace effectiveness. Furthermore, while certainly not accepted normative Halacha at present, we speculated that as norms in charitable giving change, it might lead to a Halachic requirement for communal charities to follow best practices in evidence-based charitable giving. That is, to the extent that those norms embrace more effective and more egalitarian giving, the practice of giving in Halacha may become at least somewhat more similar to the practices endorsed by EA.40

\section{References}

Alexander, Jennifer K. "The Concept of Efficiency: An Historical Analysis." In Philosophy of Technology and Engineering Sciences, edited by Anthonie Meijers, 1007-1030. Amsterdam; Boston: Elsevier/North-Holland, 2009. https://doi.org/10.1016/B978-0-444-51667-1.50041-0.

Bleich, J. David. Contemporary Halakhic Problems. Vol 1. New York: KTAV Publishing House / Yeshiva University Press, 1976.

Bleich, J. David. With Perfect Faith: The Foundations of Jewish Belief. New York: KTAV Publishing House, 1983.

Broyde, Michael J., and Shlomo C. Pill. Setting the Table. Boston: Academic Studies Press, 2020

40 The author is grateful to Dominic Roser for organising the Religious Perspectives on Effective Altruism workshop, and to him and other participants for providing early feedback on these ideas. He would also like to thank Rabbi Eli Brackman for encouraging the original formulation of the ideas that turned into the presentation, then paper. $\mathrm{He}$ also would like to thank both Ben Schifman and, again, Dominic Roser, for assistance in clarifying and revising the text. Lastly, but most especially, he wishes to thank Rabbi Yosef Ashenberg, Assistant Rabbi, Chatam, Rehovot, Israel, for assistance in further studying the origins and sources of the laws regarding charitable giving, and providing extensive feedback on and discussion of the ideas and text of the manuscript. 
Fleischman, Yosef. "Laws of Tzedakah Part II: To Whom To Give First." 12 August 2010. http://dinonline.org/2010/08/12/laws-of-tzedakah-part-ii -who-to-give-first/. 2010.

Gardner, Gregg E. The Origins of Organized Charity in Rabbinic Judaism. Cambridge: Cambridge University Press, 2015.

Harris, Michael J. "Consequentialism, Deontologism, and the Case of Sheva ben Bikhri." The Torah u-Madda Journal 15 (2008-2009): 68-94.

Marburger, Rabbi Ari. "Tzedakah and Maaser Kesafim: A Practical Guide To Giving Charity.” Torah Live. Accessed 3 September 2021. https://d1x mgiex1 rsxf4.cloudfront.net/wp-content/uploads/2014/11/Ari-Marburger -Booklet.pdf.

Pearce, W. D. Cost-Benefit Analysis. London: Palgrave, 1971.

Singer, Peter. The Most Good You Can Do: How Effective Altruism Is Changing Ideas About Living Ethically, New Haven: Yale University Press, 2015.

Soloveitchik, Joseph B. Halakhic Man, Philadelphia: Jewish Publication Society of America, 1983.

Walter, Moshe. The Making of a Halachic Decision. New York: Menucha Publishers, 2013.

Yu, Richard K. "Against A Moral Obligation to Donate.” Reformer Magazine. 22 Mar 2018. https://medium.com/reformermag/against-a-moral-o bligation-to-donate-34342ced899c. 
